\title{
Erratum to: The Effect of Histaminergic System on Nociceptin/ Orphanin FQ Induced Food Intake in Chicken
}

\author{
Morteza Zendehdel • Farshid Hamidi • \\ Shahin Hassanpour
}

Published online: 18 December 2014

(C) Springer Science+Business Media New York 2014

\section{Erratum to: Int J Pept Res Ther \\ DOI 10.1007/s10989-014-9445-5}

The original version of this article unfortunately contained a mistake. The affiliation of the author, Farshid Hamidi is incorrect. Now it has been corrected. The correct affiliation is given here.

The online version of the original article can be found under doi:10.1007/s10989-014-9445-5.

M. Zendehdel $(\bowtie)$

Department of Physiology, Faculty of Veterinary Medicine, University of Tehran, 14155-6453 Tehran, Iran

e-mail: zendedel@ut.ac.ir

F. Hamidi

Department of Basic Sciences, Faculty of Veterinary Medicine, Ferdowsi University of Mashhad, Mashhad, Iran

e-mail: farshidhamidi@um.ac.ir

\section{S. Hassanpour}

Section of Physiology, Department of Basic Sciences, Faculty of Veterinary Medicine, Science and Research Branch, Islamic

Azad University, Tehran, Iran 